\title{
Masks Again
}

\author{
Penn Kemp
}

\section{Des masques, des masques}

Il s'agit ici de la fabrication de masques réels et à la fois de masques de la personnalité. Les femmes se fabriquent ainsi une protection pour leur moi mais aussi ils peuvent se lire comme une falsification de leur être. Cette performance vise à faire danser les femmes avec les masques qu'elles ont elles-mêmes fabriqués, au plus près de ce qu'elles se savent être. Le masque comme une peau. Il n'y a plus de séparation entre l'être et le paraître. Réconciliation.

There are multitudes of people, but there are many more faces, because each person has several of them. There are people who wear the same face for years; naturally it wears out, gets dirty, splits at the seams, stretches like gloves worn during a long journey ... Of course, since they have several faces, you might wonder what they do with the other ones. They keep them in storage. Their children will wear them. But sometimes it also happens that their dogs go out wearing them. And why not? A face is a face.

Other people change faces incredibly fast, put on one after another, and wear them out. At first, they think they have an unlimited supply; but when they are barely forty years old they come to their last one. There is, to be sure, something tragic about this. They are not accustomed to taking care of faces; their last one is worn through in a week, has holes in it, is in many places as thin as paper, and then, little by little, the lining shows through, the non-face, and they walk around with that on.

Rainer Maria Rilke, The Notebooks of Malte Laurids Brigge (6) 
Masks Again · 55

\section{Masking needs/needing masks}

Private masks are useful. Public masks are tricky.

As I write, resonances from the war in the Gulf still dominate the media. The papers are full of accounts of Saddam Hussein's twisted childhood; he learned early how to mask feelings and win power through fear and intimidation. So many lives lost, so much pain.

From The New York Times, Feb. 30, 1991: "Bush has declared a ceasefire. Today in Israel is appropriately a holiday celebrating the downfall of a king in Persia who wanted to do away with the Jews several thousand years ago. It's celebrated like Hallowe'en - and better costume masks than gas masks. But no more games from Iraq, though Saddam still claims the ceasefire as his victory, still defying truth despite the obvious rout. 'Saddam cannot be allowed to save any face.' One hundred hours of ground fighting. Forty-two days of war. Gematria would claim the historical importance of that number in Semitic languages, where each letter of the alphabet has its equivalent value in a number."

Mar. 1, 1991: The New York Times reports: "Haman, the wicked Prime Minister of Persia, set a date to do his evil deed but was foiled by two Jews, Mordecai and Esther ... Children and adults planned to dress as Mr. Hussein, mustache and all, and the party mask of choice was the gas mask, which has become ubiquitous in Israel ... Traditionally, children dress in costume for the occasion and shake noisemakers when Haman is mentioned ... [this year the noisemakers are] shaped like missiles that 'have flashing lights and make noise like bombs exploding' when turned. Playing off the Purim theme of Haman hanging from a tree, Judaica World has also sold dozens of scale-model Patriot missiles sporting miniature Saddam Husseins hanging in effigy from the nose cones."

People don party masks to demonstrate their mastery of their innermost fears. People don gas masks to protect themselves from other people's untamed fears, acted out in preliminary strikes. The gas mask is the sign of our times. When military minds learn to confront their own inner fears, perhaps then the rest of us can put gas masks away. Dark sides are better confronted through party masks. By inhabiting the gargoyle, we tame it. Unmasking fears gets them out in the open where you can do something about them. Masking fears leads to more masks.

Masks allow us to do things our conscious selves would not dare. 
Carnival and Saturnalia allow the public persona to save its face. All the aspects of our selves take up their face, and dance.

Masks may release insight and pleasure, or violence and power. With this understanding, we can choose what masks we wear, and when.

I dream: In the library, a scruffy looking teacher shows me a book with pozverful illustrations which come to life as I turn the pages. The photographs are of sacred masks and sculpted heads of all the native tribes across Canada, especially those of the West Coast. But Kurdish terrorists have lopped off the ears and sometimes the noses in the photographs in order to protest the misuse of aboriginal sacred objects. Their power must be reclaimed. By defacing the pieces, the Kurds have effectively cut short the masks' pozver - and their beauty. Their mouths are red oh's. The gaping black holes where the ears used to hang now stream with blood. The masks no longer hear.

\section{Socially Approved Masks}

Masks are an iconography of the unconscious directly presented as image. Talismanic, fixed. Words that describe the mask are a distancing device already at one more remove from experience.

As Judith Fitzgerald writes: "Luminous image and note, hostages of history intersect at the crossroads/ of art over articulation."

In Don DeLillo's "Mao 11," the hero, Bill Gray, muses: 'Nature has given way to aura.' The New Yorker remarks in its review of the book that "The enemy of the word, which is worn and wrinkled by use, is the image, whose authority (as DeLillo sees it) seems absolute, as though it flowed from something not merely human - from something outside history."

The painter where I live is in his studio upstairs for nights on end, finishing paintings before taking them to his show next week. I'm kept awake by creaking floor boards, so go up and talk. The painter talks about the painting process, its duration, tracing the changes into texture. So much like the writing process, though the work of reading through a text is so different from a painting's gestalt gift, seen as it is, all at once. His painting moves from stark black and white to textured reds at a brush stroke. Masked figures mirror each other in opposition: a blue swirl of anima reflects an angular gnarled man. The painter is in control. His masks are his property.

Anne Hollander elucidates the notion of masculine control in her review of 'His Other Half: Men Looking at Women Through Art' in 
The New York Times Book Reviezv, April 1991: “Wendy Lesser bases her group of essays on the idea that certain male artists are in search of their own lost or hidden female selves, and that the success of their search can be measured by the way such rescued selves are freed by the artist and given independent life in his works of art. Ms. Lesser first describes the opposing kind of female creature in masculine art who is only an inert mask behind which her male puppet master prances, and onto which he projects his unexamined masculine views. Of this latter kind, which she calls really misogynistic, her examples come from Milan Kundera and John Updike, and she forbears further attack on them here.

The male artists she prefers are those who have used their sense of the feminine as a liberating force, and therefore feel that the other sex is the place to uncover unknown facets of their own souls so as to move their art into now emotional territory. Ms. Lesser, a feminist writer who is also the editor of The Threepenny Review, proves that their search may yield awkward and unsettling rather than perfectly balanced results. She nevertheless holds that it is always worth it, and may even be necessary for preserving the health of art and sex in the world ... Ms. Lesser's first 'divided self' is the boy painfully separated from his mother, but also more mysteriously from his putative possible sister, the female self he wasn't, when his mother first looked at him; and then the adult man divided from his own childhood self. The loss on all these divisions, she says must be acknowledged and transcended before the artist may lay hold of his creative strength."

A woman critic discussing a woman essayist, and both are still worried about the male artist, poor dear. In the last decade of the twentieth century, must we still look to males as the norm and to male models for artistic approval? Certainly women as well as men learn to mask their fears. Perhaps it is too threatening for society to confront women without masks. The question is, who is in control of the masks?

Women's inner resources can liberate powerful creative forces. But the break up of conscious masks can look like a break down. Rilke in The Notebooks of Malte Laurids Brigge (7) is witness to such a shift. The speaker is, of course, male: "The woman sat up, frightened, she pulled out of herself, too quickly, too violently, so that her face was left in her two hands. I could see it lying there: its hollow form. It cost me an indescribable effort to stay with those two hands, not to look at what 
had been torn out of them. I shuddered to see a face from the inside, but I was much more afraid of that bare flayed head waiting there, faceless."

The narrator immediately announces: "I am afraid. One must take some action against fear, once one has come down with it." And so his action is to avoid and forget the old woman; no more morbid introspection for him. What was that woman's experience? Was she suddenly free of all the faces she had put on? We never learn because the narrator shies off; we are left with the image of the naked self.

Women who are not in touch with their inner self tend to cover that self with socially approved masks. The persona is a mask of the acceptable part of the self in a symbolic order of representation. Women get good at wearing masks. But the masks are usually picked out by others.

In my teenage years in the 1950s and early 60s, we were rewarded for how well we could put on masks, just as we were expected to learn how to walk in high-heeled shoes, or not beat the boys in math. The masks with the most rewards were the ones that led to domesticity and motherhood, and if the order got reversed, we masked that for all we were worth. Once having assumed the proper masks, we were not supposed to discard them, even if they hurt, or if we outgrew them. The problem with these public masks is that they tend to stick to the skin. We put them on in hope and fun, and twenty years later we find they are ours for keeps. We are not in charge.

Old masks hurt. Making masks frees. The task is to strip away the acceptable masks and explore the ones that express our forgotten selves. I would like now to go deeper, further, inward. Uniforms, personae, aspects of our selves - these masks drop away.

\section{Mask making means mask breaking}

With women who know how to drop their outer masks, my response is entire: I merge with their being as if my own personality is falling away. There is a kind of blurring, then a sharpening of focus, where I see the woman more clearly, as essence, going back for a hundred generations, it would seem. Masks and faces play by as if on a screen.

August 1987: With me are my friends Helena Wilson, the photographer, Anne Anglin and Nancy Beatty, both actresses. Nancy and Anne are good at getting into the skin of whatever character they are 
playing. But the roles and the masks are usually designed by others to meet audience expectations.

Anne Anglin has been in the theatre most of her life. Although she has played Ophelia, Lady Macbeth, and one of the Rez sisters in her career, she too finds making her own masks for private performance meets some need that public performances of established figures, no matter how well received, do not. We've collaborated often in public performances of my plays. Her sense of visuals directs my play of language. The intertwining of lives, the masks we put on. "My Life as a Performance Piece." But now we are about to embark on a private theatrical enterprise.

Anne has an idea. For each season, we will make a mask in harmony with the corresponding direction. We begin with a drawing to focus our intention and then make masks. To do so, we build a plaster form on which all the other masks will be based. To make this replica of our features, we take turns wrapping each other's face in cotton gauze wet with liquid plaster. And then we wait, eyes closed, unmoving, while the plaster of Paris hardens around our features.

We are making a death mask to enjoy life. We must feign death to get the likeness exact. The masks harden into a perfect white chrysalis, the abstraction of our own faces. We are released into play, choosing the mask or letting it choose us. We are in charge, but without controlling. We decide whether the mask will be finished as a butterfly, a bear, or a spirit.

Helena makes her mould, and takes photographs as the others are made. The next time she joins us is at the end of the cycle, a year later, when she photographs us dancing out our masks.

For now, the next step is to make a relief mask out of clay. Making life out of clay, colloidal, slippery as sin, tiny particles sliding like monads into replicas of our lifeline etched faces. Three Eves making faces.

When the clay masks are finished, we move to the third stage of our mask-making process. We pour the plaster into the set clay, which is later removed carefully, after the plaster encasing has dried. The clay is liable to crack and break. We are lucky if it comes out in one piece: luck determines if we keep this mask.

We cover the inverted, negative, plaster mould with six layers of papier-maché, to create the final mask we will use in our ceremonies. 


$$
\text { 60. Tessera }
$$

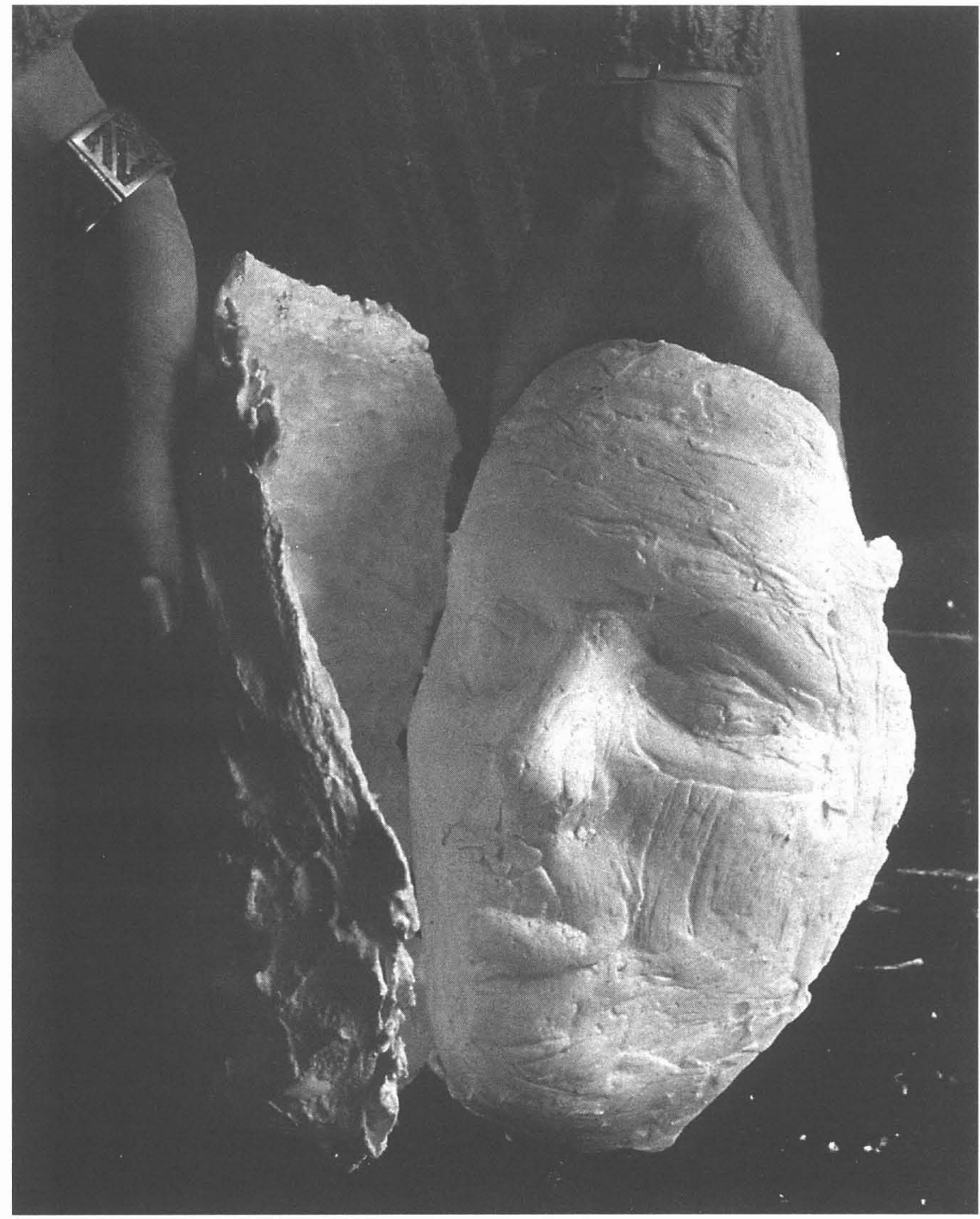

Helena Wilson 
While lignin dissolves and then hardens, we press out exuberant noses, add foxes' ears or round whistling mouths. This time, we get to judge how we want to look, and yet we let our hands be led. This is no beauty contest. Paris with his apple can get plastered for all we care. Who was that masked stranger? That was no stranger; that was my life.

We have made our mask shells, and now we must decide how to give them life, how to let them breathe. The balance between is the art of judgement. We respect the power of the masks to capture our strengths, and to speak for us. Each is a discovery, entirely its own being. We want to be surprised.

There is something about the act of making masks that unites us with each other, with our childhood visions of creating something out of mud and leaves and feathers, and with other generations of women who lived in societies which respected the right of women to lead their own ceremonies.

We make masks for each season, so we will be protected through the winter, summer, spring and fall. The alignment to the four seasons is as old as the first culture and this is our attempt to honour that wisdom.

August 13, 1987: Over at Anne's, we pour the plaster over the clay mask of summer, and take the mould out. It's wonderful to be working with our hands; we have to be completely present in the moment. Such fun to make things, to let them make themselves, to play.

My summer mask paints itself in red, violet and gold. Bold indeed, and quite unlike the eagle I had envisioned in a preliminary drawing, bolting out of the sky like July lightning. Perhaps that energy will emerge when we're playing the masks. The summer mask has become almost a clown, though Anne sees it as full blown fecundity. Its personality shines especially bright now.

The summer mask for me demands the most. Swirls of red and purple, yellows and gold cover the papier-maché. Feathers sprout from the ear holes. Where do the colours come from? From deep connections, from reactions to having to dress in acceptable colours, to reaction to a lifetime of Fire and Ice commercials? Anne tells me anger is the easiest emotion for young actors to improvise. It is the boldest colour, red. Certainly, it's the chameleon, power willing to express itself and not hold back.

The summer is sun, the all-seeing, shining father. Very aggressive, 
as Anne comments, when I don the mask and begin to strut a performance. Life-giving, he can be destructive, creating desert. The Summer mask seems to represent All the Patriarchy for me. Such power. In astrology, my male principle, Saturn is in Cancer, the home: a tricky place for the rigid forms of the law-giver. He needs the mother's balance, moon nurturing, protective.

The summer mask is guide to the underworld and to the upper world. His dreams teach me the way to the elements and to sky lore. He translates the language by osmosis into my understanding when I don the mask.

September 27, 1987: Working on a mask that will represent the fall, that time of harvest, sacrifice and surrender, completion. Good to do before the High Holidays and the Jewish / Celtic New Year, entry into the sacred season. My fall mask shifts from its original Chinese conception to Egyptian. The cow, Hathor, perhaps, giving all. Luckily, I have the original clay mask, which remains very Chinese. I've been working on fall and summer too close together, so there's some smearing at the edge of concept.

The masks inform us, even in sleep, according to their season. I dream: At the front of the tour bus, a woinan guide is speaking. She points me out as a special instance. "Who," she asks, "if they knezv they carried an Egyptian guide above their head, would not vierv him as a mirror?" She describes the guide with his blue and gold headdress, naming him just as my friend had described him to me earlier. The guide on the bus suggests I offer silver, and I mean to question her about that, preferring to exchange spiritual wisdom, not pay for it. So I rise from my aisle seat, and alight.

In keeping with Egypt as fall, I cover the white cowled pupa with rays of lapis lazuli and royal purple against a golden background. The golden fall, the setting sun, the energy of the coming night, all are in this mask. It's beginning to look like Tutankhamen's sister/lover/fellow god.

The West for the Egyptians is the place where the dead are buried in waiting for the next life. But rather than a place of mourning, the desert landscape hides tombs that contain intense joy. It is as if the promise of everlasting life has been already fulfilled in the place of the tomb. The mask radiates.

We must be enacting three wise women come from the first fertile valleys, from the female-centred peaceful cultures, before the stirrup of horsemen and gynaecologist imprisoned us. 
December 21, 1987: This winter we create our winter masks. Mine is cool and blue in contrast to the brighter masks. It is the blue of holidays, of lakes and pools and skylines blending into lake horizons. A dark swirl under the eyes, resonant of kohl, of mysterious blue essences coming from Egypt and the summer, or of reflections from the ancient ice of icebergs. This mask knows nothing of appropriation by advertising for blue light, or, if knowing, is coldly indifferent. This mask is the Logos, clear light.

April 11,1988: The last mask of the four, which we leave to spring, is my favourite. She is a sweet faun, a pixie, finished in bands of green and gold, lips and horned ears highlighted in red. She is the rising sun, the sprouting corn, the source of life and light and connection with the cycle of seasons.

The four masks surround me, each on the wall. To complete the circle, we create three more masks to represent above and below, and finally the clown at the centre. Here we are following the teachings of Richard Pochenko, master clown.

May 13, 1988: Tonight Anne and Nancy and I are completing our masks. The above mask is all spirit blue, pointed like a bird. Mine came out funny like a peaked mosquito, about to lift off. She is laughter, light, pretending to hide behind a camouflage shield, not about to take herself too seriously.

My below mask is the most like my shadow self, my underworld being. This red shield is not rage so much as pure energy, undifferentiated into emotion. She is a bold little lion face, blood red, and scarified with black lines. I love her, the ease of movement, the rest and action. As long as she is content, she purrs. When she is hungry, she stalks, the impersonally focused hunter. Having no thought, she is without guilt or remorse. Living in the eternal present, she is animal and archetype: I know her well.

What I do not know is the summer mask, who has come to represent that primal energy in form, in persona, in society. My summer mask is a twisted red and purple mask I first felt was patriarchal. But set beside the below mask, it also contains the aggrieved and suffering woman and the hurt child. It is the family, that which nurtures and turns upon. It is how convention acts upon the individual. How the individual is twisted by the dictates of society and her own experience. I look upon the summer and honour her attempt to represent the truth from below. 
Let the above mask bring the summer mask peace; as mother she has done well, done the best that she could. Let the winter mask bring her calm.

\section{Unmasking pain}

July 23, 1988: I've been off for two days with Anne and Nancy maskdancing at Blyth. The night deepens as we begin. We dance the masks in the front yard of her new place, overlooking the Maitland River as the moon comes up behind. A great pyre has been lit of the old wooden shingles the men have pulled from the roof. Three local women have joined us to dance the masks, women who have done Goddess work. Their trust and openness makes the night possible. Anne goes into automatic mode and lets each mask select its wearer. I am handed my below mask, a small red gargoyle with an attitude.

Anne's new house is perfect for her; she has found her vocation. Here in this almost oxbow, the Maitland River curls upon itself like oroborous, a moat that divides the road from the property. The crossing is a low concrete bridge that will flood in spring. Geomancy: the house is in perfect alignment with the hill opposite, a power mound. When I dance her mask, I feel her work as steward of the hill, and her challenge to explore its inner spiral. It's become known as "Annie's Magic Hill."

Both Anne and Valery dance my below mask as rage. Anne feels my summer mask is all pain, all sorrow. She is determined it needs to be tempered by the cold wind of the winter. Logos. I am not sure that the distancing technique of intellect is appropriate to the contorted passion of the summer. I would rather bring that upset down to the primal energy of below. There it can rest; it can find its own expression in form and hold true throughout the upper layers of persona and convention.

August 4, 1988: Anne, Nancy and I are together again in Toronto. In the soft muted violets of dusk, we're down by the Waterworks at the lake. Energy surges through the masks to animate our bodies. We whirl in the light of the settling sun. We are transformed. Our ordinary roles and masks fall away. We are alone, yet linked with the energies of all those who have worn similar masks, and performed similar rituals in all the tribes of human history. We are freed from the constraints of audience. We don't have to worry about stepping out of the expected role: we are free to create as the spirit moves us. We chant, we laugh, 
we whirl in a perfect kind of freedom. We have become what we want to be.

My summer mask is purpling, becoming the dark clown my father presented to the world, his death mask, the painting Anne did of his spirit. Very male, very heavy. Wearing this mask, I find the formal military structures of the marble Waterworks orderly and pleasing in their high proportions.

My father wore several masks. His public personae were as navy officer and insurance executive. The private one was as painter. The split resulted in a massive coronary. It may be true that my decision to be a writer was an attempt to live out his dream in my own way, without the compromises that the Depression necessitated for him.

For the first time I experience what it is to be male, approaching Nancy in her corn maiden mask as she sidles away. But when she comes close, I move away: no intimacy for me. To Nancy and Anne, I am funny in my broad macho strutting. But the mask does not find its own humour until I see Nancy perform it, Chaplinesque. Easy to find its dance though, a native earth dance, pounding the earth in high step rhythm. This mask is Will, while the West represents surrender.

Tonight, exhilarated and exhausted by the masked dancing, the concluding lines of a poem I have been working on come to me:

"Let me finish my work before sweet

domesticity does me

in again."

\section{Interior Masks}

All the masks are positioned around me, chatting away to themselves above my head as I type. Winter whistles logical reminders of the mind to the passionate Summer. The little fox mask of the Spring chirps away to the Fall mask opposite her, the Egyptian. Sunlight catches in the sequins of the Bedouin blue cap that I have draped over the green faun's ears.

We haven't yet done our centre mask, the one that will see us through to wholeness. It can only emerge after all the others are complete. So much of my life, the clown in me has had to be suppressed. It needs to come out, and the mask gives me an occasion.

August 26, 1988: I am cajoling the spoiled wilful child in me who wants things her way, wants to look good, not to lose face. That lost 
child I can mourn. She'll do anything for control and attention. Why does she want to create tragedy and drama? The ego of this little girl has to be transformed. Of course she doesn't want to let go of control, her only safety. What can I offer her? Something larger, giving her total acceptance and nurturing. Her positive intent is to feel secure, so I imagine cradling her.

I give her the green faun mask of the spring to play through. She likes the stimulus of nature, so I venture down the Lower Valley road, hiking up the steep skidoo trail to the top of the valley. There, admiring the greens of cedar and maple on the other side of the valley, I sit on an abandoned stone foundation chewing catnip and breathing peace. What a view.

August 29, 1988: Anne is coming up for the day, to do a ceremony to find our clown. At Eugenia Falls, we wander the cedar forest, such easy walking on dry needles, with no underbrush able to survive the hushed dim light. Only the top branches reaching bright sun are green. The light dappling through the dead boughs is red, red glinting off polished cedar roots, their bark scraped away by water or porcupine. We come to an islet in the stream down from the cedar forest. We sit in a mass of peppermint, facing a willow that flourishes in the water among the rocks. We breathe the Sufi meditation of the elements: in and out through the nose for the earth, in the nose and out the mouth for water, in the mouth and out the nose for fire, in and out the mouth for air. I hold the breath for ether. Beside me is a white orchid in full bloom.

Anne is intent on finding the central mask. Back home, we draw, letting the clown out onto the page. I sit in the centre of my room, on the old Moroccan rug, the masks singing on the walls around me. How can I include them all? For each direction I face, a different clown emerges: turtle for the fall, toad for the winter, frog for the spring, heron for the summer. No composite animal emerges. All these figures are so familiar to me from pieces I have written: the polarity of Toad and Heron, a turtle from Trance Form. I asked for a new image to constellate the power of the masks.

In the centre, words surface: "I AM THE POWER OF LOVE. WHO IS THERE TO MEET SUCH A ONE?" I draw a woman, her chakras encircled, her body surrounded with the words, "Only She Who Steps Into Her Power." But still, this is not the composite image I seek. Behind all these grand declamatory figures is one that has been trying 


\section{Masks Again · 67}

to emerge, to get my attention, beckoning me urgently from the shadows. Someone I'd hardly noticed till now, so deep in shade was she. I finally draw her, a shy red girl I know very well. Saucer blue eyes, rosy cheeks and a fiery mass of ringlets. This is me at two or three, figuring out the wonders of the world. Transposed from drawing to mask, she becomes a clown indeed, painted in outrageous pinks and fuchsias and purples, with a wen like knob that was supposed to be the visionary third eye. Heavier than the others, she is the only mask that is not full face. Under her cheeks is my mouth. I hang her on my summer wall over the bed.

August 30, 1988: After lunch we take the drawings of little girl and south patriarch to the willow island, and ceremonially burn them. We breathe the meditation of the elements. The ashes I place onto paper, and send down the rapids over the falls. It is done. The child is held in peace with the father.

\section{Masking Dreams}

Masks recur in dreams, vehicles for articulating the inexpressible. My hard disk drive is full of recollected dreams of masks, guides to the unconscious. Masks unmasking masks that maim and let us play.

I dream: Someone tells me there is a surprise waiting for me in the cottage up the hill. With a rain coat over my head, I go up to see: it's my little niece and nephezus, visiting for the day. A rare chance for us to play. I paint them up as cats, so they purr and scratch and mezv. The younger boys and Lydia are thrilled with their face masks.

Dreams connect us to ourselves through masks, recurring, as this one from last night illustrates. July 4, 1991: Marshall McLuhan is giving a seminar at Western which I attend with four or five others. Because I seem to be on a roll of synchronicities, I have been keeping track of thein for the class. Now I run up to the professor, excited. "Dr McLuhan! Guess what synchronicity just happened!" McLuhan, in hearing me, has taken the green granny apple from my hand, and has munched most of it up in his intense absorption in the story. I regard it with mock rue. "So, this is my reward. My apple is eaten." Actually, he's only had time to gobble one side, but I give him the other. His crooked little teeth are rotten, dripping spittle, but his gray eyes are glittering with delight, deeply set in that weathered old mask of a face.

One of the other students goes down to the seminar, as the class is about to start. His face has been stretched back somehow to form an Egyptian mask rimmed round by his blond hair. His blue eyes are lapis lazuli and his skin is a 
golden colour. How does he manage to look like Tutankhamen? Grinning, he tells me he just had to pull back the muscles in his cheeks and they stay stretched. But it happened naturally, in response to my mask of the West, which looks very Egyptian. "Another synchronicity," he explains.

It is only now I notice the similarity in the dream masks, from 1987 to this.

Dreams can connect us to each other, and heal. On Anne's birthday, A pril 17, 1991, I dream: Anne and I meet to talk... I don't remember what about; evasively she twists azvay from words, her lean frame green, tozvard the mask of gesture. I enter into her performance, and watch the play unfold.

The cat crawls along the roof of the platform in the dark hall in which we are rehearsing. It is followed by a cat woman who imitates exactly its gestures of stretching or raising its fur, and yozols along with the animal. It is as if she has assumed the cat. Perhaps her whole body is in a cat mask. Down below, we performers watch this performance with trepidation, concerned lest the woman fall. Anne and I are acting, with Paul directing. Another director is in the background, having props moved in and out. It is night somezwere in the loft district, I suppose at Passe Muraille; the hall is dimly lit and dusty.

The scene shifts to a bucolic day in spring. As I wander along the path, the old man is sweeping out his ivy-covered cottage while the sun beams in the open door. Five cats, marmalade, tan and black, are frolicking in and out of doors. "Do you feed your cats? Do you allow them to stay in overnight?" I ask him over his zuhite picket fence. "No," he replies, stopping to lean on his broom. "The cats are allowed in and out during the day, but I never feed them. They must fend for themselves on rats and mice." They look perfectly healthy, their coats shiny. I'm impressed.

Hearing my dream, Anne asks for details: "Was it a black cat, bigger than usual?" "Yes, with its hair on end, a fright, like a Hallowe'en cat." Anne sighs in recognition: she had that dream as a child, and is still frightened by it, still waking up to face the fear in the early morning before daybreak - about the time I had this dream. "And the woman, what was she like?" A ferocious image pops into my head, the figure on the roof.

"She was like your animal self, very agile, crawling up along the roof like that, but not quite human. Like a change artist, she was dressed in black, her face painted black, whiskers glued on like a cat's. I understood she was connected with you somehow, almost by the wire of your fear. She gloated on your fear, making weird faces at you, almost behind my back. I wasn't afraid of her, but you were 
sensitized. The experience was unsettling for me because of its oddness; I understood this rehearsal loft was your space. I've had several dreams lately of a white ballooning ghost mask, but this one was dark, cat-faced, and directed to you. It was threatening because you had seen it all before."

Like me, Anne has been facing the mask of her shadow, which, as Jung announces, presents itself in middle age, and she doesn't like what she sees. So I continue with the image of the bucolic cottage, cats playing in the sun, to bring some peace.

\section{Private/Perform/Public}

It is time for us to make private dreams public. In theatrical terms, how can audiences inhabit the dream with us? How do we share this privately generated electricity with theatre-goers conditioned to receive a play as words on a stage? How can we make the dreams accessible? Without diluting them to infiltrate the screens set up by male critics, without donning the masks, images of women, that critics give permission to wear?

In our collaborations, Anne and Nancy and I have used private performances to heal, to liberate joy and dance, to release pain, to enter the centre of our creativity. This exploration is profoundly female, but it has been carried out almost entirely without words. The masks are our representation of what it is to be a woman in this world. Mime, however, is mute.

How can this symbolic language of gesture be described in feminist discourse? I don't think in terms of 'interface.' To write the piece, I resort to conjuring. Lighting candles and incense, I put on the mask of the clown and summon the voices of the masks around my walls.

How do I write the essay as my experience and not an appropriation of other cultures? At this historical moment, we are at last sensitized to native voices and wish to respect their tradition.

Discovering/creating our own masks, we have found that they are guides to hidden aspects of ourselves. In putting on the mask, we find enormous liberation. Illuminations of our lives, the masks make us whole.

Masks that we have chosen to assume channel us into interior spaces we have long walled off. The masks bear us safely to the secret enclosures of our creativity and back again, as we take them off. The exploration is safe because it has a beginning and an end, within the 


\section{$70 \cdot$ Tessera}

brackets of donning and taking off the mask. The closure returns us to the world with new knowledge. But the voyage is one of discovery, we are not puppeteers.

Dancing our masks, we connect with each other and ourselves. The audience is almost immaterial. The process gives satisfaction as much as the performance. We choose participation and creativity, not the separation from the theatrical audience which has been trained to be receptive and passive. We want to drop the tension between selfexpression and communication with audiences which is predicated on going through the male establishment. We want a space for players and audience in which to dance and spin and have fun together. 


\section{Masks Again · 71}

\section{Performance Pieces of Penn Kemp}

Bearing Down, Seattle FM (4 voices) 1973

Wedding Piece, The Western Front, Vancouver (slides, movie) 1974 Trance Dance Form, A Space, Véhicule, Harbourfront (with actress Anne Anglin) 1976; World Symposium on Humanity; Artsevent, Hamilton, 1979; Scarborough College (pianist Coby Stoller) 1980; Findhorn Arts Festival 1985 (with jazz pianist Karl Becker) Animus, ArtPark, Buffalo (with percussionist Charlie Morrow); peopleart, Buffalo (with percussionist Charlie Morrow); Radio Freerainforest, Vancouver 1984; Sound Symposium, St. John's Newfoundland 1984

Once Having Knozun You, K.A.A. Kingston (with dancer Vicki Tansey); International Poetry Festival, NYC (with Vicki Tansey) 1980; The Lincoln Centre New Wilderness SummerSolstice Celebration 1981; Findhorn Arts Festival, Celtic Festival, Toronto 1985;

Cathedral of St. John the Divine, NYC (with Charlie Morrow) 1985

C'louds, Free Times Café; Peterborough Arts Space (with Anne Anglin); Greenwood Community Centre (with Anne Anglin) 1987

Bone Poems (dancer, drums, dijeridoo), Findhorn Arts Festival, Scotland, Stroud, England (External Affairs Tour, 1984); NYC 1985 Audiographics, New Wilderness Foundation

Inspiritrice, parallel galleries in Edmonton, Vancouver, Toronto, Calgary

Incrementals, NYC 1985 Audiographics, New Wilderness

Foundation

On Your Oron Spoke, The Great Canadian Poetry Weekend,

Collingwood 1981; Children's Festival, Toronto 1989 When the Heart Parts, Free Times Café, Toronto Klang Poetry, Bonn; Landshut; Munich, Germany, External Affairs Tour 1985 Hera, Lee's Palace (with Anne Anglin and Nancy Beatty) 1986 Ear Rings, Music Gallery, Toronto (with violinist David Prentice) Throo, Music Gallery, (with David Prentice); S.C.M. Bookstore, Toronto (with David Prentice) 1989 
$72 \cdot$ Tessera

\section{Plays Produced}

Angel Makers, Redlight Theatre; Toronto General Hospital; Hollywood, CA.

Eros Rising, Theatre Passe Muraille.

The Epic Toad and Heron, Toronto Island Community Centre; schools.

\section{Tapes of Performances}

Trance Dance Form (Soft Press, 1976); Animus (Caitlin 1977); C'louds; On Your Own Spoke; Inspiritrice; Ear Rings (Underwhich Editions 1987); Throo (Moonstone Press 1989). 